\title{
Total Facelift: Forehead Lift, Midface Lift, and Neck Lift
}

\author{
Dong Man Park \\ Bio Plastic Surgery Clinic, Seoul, Korea
}

Patients with thick skin mainly exhibit the aging processes of sagging, whereas patients with thin skin develop wrinkles or volume loss. Asian skin is usually thicker than that of Westerners; and thus, the sagging of skin due to aging, rather than wrinkling, is the chief problem to be addressed in Asians. Asian skin is also relatively large in area and thick, implying that the weight of tissue to be lifted is considerably heavier. These factors account for the difficulties in performing a facelift in Asians. Facelifts can be divided into forehead lift, midface lift, and lower face lift. These can be performed individually or with 2-3 procedures combined.

Keywords Rhytidoplasty / Cervicoplasty / Face / Forehead / Neck
Correspondence: Dong Man Park Bio Plastic Surgery Clinic, 405 Gangnam-daero, Seocho-gu, Seoul 137-856, Korea

Tel: +82-2-512-9300

Fax: +82-2-533-8123

E-mail: pspdm@korea.com

No potential conflict of interest relevant to this article was reported.

\section{INTRODUCTION}

With the development of science and medicine, the human life span has become much longer, and the demands for anti-aging surgery have grown. Unlike general aesthetic plastic surgery, which addresses unaesthetic congenital qualities, anti-aging surgery focuses on recovering the patient's youthful appearance that has faded away with age. Some of the problems that appear on the aging face are wrinkles, blemishes, age spots, volume loss, and sagging of tissues. When seen close up, wrinkles are the major cause of appearing old, while from far away, volume loss and drooping of tissues are the major causes of appearing old.

Patients with thick skin mainly exhibit the aging processes of sagging, whereas patients with thin skin develop wrinkles or volume loss. Asian skin is usually thicker than that of Westerners; and thus, the sagging of skin due to aging, rather than wrinkling, is the chief problem to be addressed in Asians. Asian skin is also relatively large in area and relatively thick, implying that the weight of tissue to be lifted is considerably high. These factors account for the difficulties in performing a facelift in Asians.

In a majority of people, wrinkles start to form in the late 20 s in places with the thinnest skin such as the periorbital area, and as these people grow older, volume loss and drooping of tissues develop. Wrinkles can be categorized as superficial wrinkles, mimetic wrinkles, and folds [1], and the mechanism of their formation is as follows:

Superficial wrinkles develop from pathological changes due to aging, which is mainly the atrophy of all components of the skin. The number of melanocytes and that of Langerhans cells decrease in the epithelium as people grow older. In the dermis, type I and type III collagen exist at a ratio of 6:1, but as aging ensues, the synthesis of type I collagen decreases and the relative amount of type III collagen increases, which allows more drooping of the skin [2]. Collagen makes up $70 \%$ to $80 \%$ of the dry weight of the dermis, and as it decreases, dermal thickness is decreased by $6 \%$ every 10 years [3]. As people grow older, the skin and subcutaneous fat become thinner, and due to chronic exposure to ultraviolet light, the collagen and elastic fibers in the dermis decrease and 
lose elasticity to create superficial wrinkles [4].

Mimetic wrinkles develop from the repetitive contraction of the 17 pairs of facial expression muscles over a long period of time. Glabellar frown lines, forehead wrinkles, and crow's feet are formed from the repetitive action of the corrugator supercilii muscle, frontalis muscle, and the orbicularis oculi muscle, respectively.

Folds form from differences in anatomical change due to aging in individual tissue components. As people get older, the six layers of tissues droop and sag downward. During this process, the soft tissues move a different amount between each layer, and the most movement occurs between the superficial fascia and the deep fascia. However, in the face, there are various retaining ligaments that hold the superficial and deep fascia together, and since these ligaments are tougher and stronger, they do not sag down as much as the other tissues. In the areas where these retaining ligaments hold the skin, the deep tissues do not sag down, while in other places without these ligaments, skin and fat tissues sag down more due to gravity. Further, these sagging tissues are caught at places where the retaining ligament is holding on the skin, creating bumpy appearances or deep folds $[5,6]$.

To treat superficial wrinkles, dermabrasion, chemical peeling, or laser resurfacing is effective; for mimetic wrinkles, botox, filler treatment, or autologous fat transplantation is effective; and for folds, a facelift is the most effective.

Volume loss due to aging occurs in all tissues, including bone, muscle, fat, and skin tissues. Various changes occur in all parts of the body with fading sexual characteristics due to a decrease in growth hormones and female/male sex hormones. Growth hormone aids the growth of bone and muscle in adolescents, and helps maintain muscle mass and distribute fat throughout the body in adults. As the growth hormone secreted from the pituitary gland decreases muscle mass and the basal metabolic rate decreases, the fat is not distributed as evenly, with increasing amounts of visceral fat. In the face, volume loss due to a decrease in the fat tissue is the most prominent phenomenon, and fat transplantation is recommended $[7,8]$. Volume loss due to a decrease in the muscle mass may be corrected with exercises of the 17 pairs of mimetic muscles. As the muscles in the extremities, facial mimetic muscles also increase in strength and volume with exercises beyond the usual threshold.

Drooping is mostly caused by gravity, and a facelift is the most effective method to pull these tissues back upward. Hollander [9] first introduced the facelift with excision of tissues along the hair line, and the procedure has been advanced by many surgeons since then. However, most methods were limited to the manipulation of the skin and the subcutaneous layer, until Skoog introduced the superficial muscular aponeurotic system
(SMAS) lift in 1973, with Mitz and Peyronie [10] describing the anatomy of the SMAS layer in the literature in 1976. Since then, the SMAS lift has made a stunning advancement. Psillakis et al. [11] introduced the subperiosteal facelift in 1988, and Hamra $[12,13]$ introduced the "deep plane facelift" in 1990, which was superseded by the "composite facelift" in 1992, and then Stuzin et al. [14] and Mendelson [15] introduced the extended SMAS technique with dissection of tissues beyond retaining ligaments to effectively lift the nasolabial fold.

Recently, a myriad of new methods of rejuvenating an aged face have been introduced, such as techniques using various threads. However, these non-invasive and minimally invasive techniques have their specific indications, and pros and cons [16-19]. These procedures may be easily performed on busy office workers as they are relatively simple with shorter recovery periods, but they also have shorter periods of effectiveness. Conventional facelifts may have more procedural risks and morbidities, but can lead to predictable outcomes with long-lasting effects, which is why these procedures may be ideal for patients who can afford a recovery period of $1-2$ weeks.

Facelifts can be categorized into forehead lifts, midface lifts, and neck lifts. These procedures may be performed alone or in conjunction with each other.

\section{ANATOMY}

\section{Forehead \\ Muscles}

The key to performing a successful forehead lift lies in balancing the forces of the eyebrow elevator muscle (frontalis muscle) and the depressor muscles (depressor supercilii muscle, corrugator muscle, procerus muscle, and orbicularis oculi muscle).

\section{Motor nerve (temporal branch of the facial nerve)}

The temporal branch divides into 2-5 smaller branches. The anterior branch penetrates the parotid fascia just inferior to the zygomatic arch and exits the parotid gland to run below the SMAS and pass over the zygomatic arch to a superior direction. After passing the zygomatic arch, it runs below the superficial temporal fascia and passes through the deep surface of the frontalis, orbicularis oculi, and corrugator muscles to innervate the muscles. The posterior branch exits the parotid gland from the posterior border and runs over the zygomatic arch to the temporal region to innervate the anterior auricular muscle and the temporoparietal muscle. Topographically, the temporal branch runs in the direction of a line connecting two points: a point 0.5 $\mathrm{cm}$ inferior to the tragus to a point $1.5 \mathrm{~cm}$ superior to the lateral end of the eyebrow [20]. 


\section{Sensory nerves}

The supraorbital and supratrochlear nerves are branches of the first division of the trigeminal nerve. Both of these nerves are susceptible to injury as they emerge from the bony foramina where they are more adherent and less easily moved or stretched [21]. After passing the superior orbital rim, the deep branch of the supraorbital nerve runs laterally and superiorly between the galea aponeurotica and periosteum. In the forehead, it runs $1 \mathrm{~cm}$ medially to the superior temporal line parallel to this line, and divides into many branches near the coronal suture, penetrating the galea aponeurotica to provide sensation in the frontoparietal region. The superficial branch, after passing the superior orbital rim, branches immediately and penetrates the frontalis muscle to provide sensation to the forehead [22]. The supratrochlear nerve courses through the corrugator muscle.

\section{Retaining ligaments}

The retaining ligaments can be categorized into true ligaments, septums, and adhesions. Septums are fibrous walls, that connect the periosteum or deep fascia to the superficial fascia. Tissues attached to a septum can only move perpendicular to the septum, and not in parallel. Most septums are located in the temporal and periorbital regions, such as the inferior temporal septum, superior temporal septum, and periorbital septum. Adhesions are fibrous or fibrofatty tissues that connect the periosteum or deep fascia to the superficial fascia. These are basically two-dimensional structures, and tissues attached to an adhesion have certain limitations with respect to movement in any direction. Septums and adhesions do not reach the skin and end in the SMAS layer; therefore, tissues superficial to the SMAS may move considerably. The temporal ligamentous adhesions and supraorbital ligamentous adhesions are examples of adhesions located in the temporal and periorbital regions [23].

\section{Face}

The face is composed of six layers: skin; subcutaneous fat; SMAS (superficial fascia); mimetic muscles; parotidomasseteric fascia (deep fascia); and facial nerves, arteries and veins, the parotid duct, and buccal fat [24]. For people in their 20's, the typical length from the helix to the alar of the nose, and from the ear lobule to the chin is $12 \mathrm{~cm}$ and $13 \mathrm{~cm}$, respectively. For people in the 30's and 40's, this length changes to $13 \mathrm{~cm}$ and $14.5 \mathrm{~cm}$, respectively, and in the 50's and the 60 's, $14 \mathrm{~cm}$ and $16 \mathrm{~cm}$, respectively. As people age, the skin length increases $1-1.5 \mathrm{~cm}$ per decade, which means that, by removing $1-1.5 \mathrm{~cm}$ of skin, these patients can go back to their state 10 years before $[5,6]$. Subcutaneous fat is widespread below the skin, and loss of subcutaneous fat makes up the largest amount of tissue loss as people age.
As compared to the increase in the surface area of the overlying skin, subcutaneous fat shrinks, causing a deflated balloon-like appearance.

\section{Superficial muscular aponeurotic system}

SMAS is superiorly connected to the superficial temporal fascia, which is connected to the galea aponeurotica. In the lower facial regions and the neck, SMAS is connected to the platysma muscle. SMAS originates from the tragus and inserts into the nasolabial fold. In the parotid region, there is no fat between the deep fascia (parotid capsule) and the SMAS layer; therefore, SMAS directly adheres to the parotid capsule, which is clinically important [25].

On the medial side, SMAS separates into the superficial and the deep fascial leaves, which enclose the zygomaticus major and minor muscles, and runs into deeper layers medially to fuse with the orbicularis oris muscle at the nasolabial fold. To deliver the maximal pulling force of the SMAS to the nasolabial fold, dissection under the SMAS layer should be performed up to the zygomaticus major muscle, and after passing the muscle, the dissection layer should be superficial to the SMAS layer [26].

\section{Muscles}

The muscles of facial expression are divided into two groups: the superficial and the deep groups. Most of the muscles of facial expression belong to the superficial group and lie superficial to the plane of the facial nerve. The muscles that belong to the deep group are the mentalis, buccinators, and levator anguli oris muscles, which lie deep in the plane of the facial nerve. All of the muscles encountered in facelifting, including the platysma, orbicularis oculi, zygomaticus major and minor, and risorius muscles, belong to the superficial group [24].

\section{Motor nerves (facial nerves)}

Most of the facial nerves run below the deep fascia. In the preauricular region, they run below the superficial lobe of the parotid gland, the masseteric fascia in the masseteric region, the deep fascia in the buccal fat pad region, and more medially just below the SMAS to pass through the deep surface of the facial mimetic muscles to enter the muscles. The facial nerve divides into five branches: temporal branch, zygomatic branch, buccal branch, marginal mandibular branch, and cervical branch.

The zygomatic branch divides into the superior and inferior branches after exiting the parotid gland. The superior branch passes below the upper $1 / 3$ portion of the zygomaticus major muscle, and the inferior branch passes below the lower $1 / 3$ portion of the zygomaticus major muscle, dividing into smaller branches to innervate the orbicularis oculi, levator anguli oris, 
buccinators, levator labii superioris, and zygomaticus major muscles. As the zygomatic nerve runs superficially just prior to entering the zygomaticus major muscle, particular care must be taken to not injure the nerve $[24,27]$. The superior branch of the zygomatic branch usually divides into deep branches (95\%) and only into superficial branches in $5 \%$ of the cases. The zygomatic branch and the buccal branch communicate in $70 \%$ to $90 \%$ of the cases, and both divide into superior and inferior branches. The zygomatic and buccal branches exit through the anterior border of the parotid gland and run below the masseteric fascia before exiting the masseter muscle to run below the SMAS.

The buccal branch exits the parotid gland to run below the masseteric fascia. In the buccal fat pad region, it runs between the surface of the buccal fat and the SMAS, and runs more anteriorly just below the SMAS. The deep fascia covering the buccal fat pad is the thinnest in this region and adheres closely to the SMAS. The superior branch communicates with the zygomatic branch and innervates the buccinators muscle, and the inferior branch communicates with the marginal mandibular branch and enters the depressor anguli oris muscle [28].

\section{Sensory nerves}

The infraorbital nerve is a branch of the second division of the trigeminal nerve. Injury to this nerve results in numbness of the lateral nose, cheek, upper lip, and inferior eyelid. The mental nerve is a sensory branch of the third division of the trigeminal nerve. Injury to this nerve results in numbness in one half of the mucosal and cutaneous surface of the lower lip and chin [21].

\section{Retaining ligament}

Retaining ligaments are divided into two types, depending on the origin. One of the types is the osteocutaneous ligament, which originates from the periosteum and inserts into the dermis, and includes the zygomatic ligament and mandibular ligament. The other is the fasciocutaneous ligament, which connects the SMAS to the deep fascia in specific regions of the face, and includes the parotid ligament and the masseteric ligament [14]. The zygomatic ligaments are located along the inferior aspect of the zygomatic arch, with the main zygomatic ligament originating from the transition point between the zygomatic arch and the zygomatic body, 4-5 $\mathrm{cm}$ anterior to the tragus [29].

\section{Perforating artery}

The transverse facial perforating artery, which frequently causes bleeding during facelifts, is located $31 \mathrm{~mm}$ lateral and $37 \mathrm{~mm}$ inferior to the lateral canthus. The submental perforating artery is located in the middle, between the menton and the gonion [30].

\section{Neck}

The soft tissues of the neck are arranged in multiple layers forming concentric circles like those of an onion, similar to the face (Fig. 1). The two basic fascial layers, the superficial cervical fascia and the deep cervical fascia, are arranged in concentric circles. Below the skin, the subcutaneous fat is present, and below it lies the superficial cervical fascia. The superficial cervical fascia invests on the platysma muscle, which is connected to the SMAS, superficial temporal fascia, and galea aponeurotica. Below the superficial cervical fascia is the subplatysmal fat, and below the fat is the deep cervical fascia. The deep cervical fascia is formed from the investing cervical fascia, pretracheal fascia, and prevertebral fascia. The investing cervical fascia is connected to the parotidomasseteric fascia, which separates into two layers, one deep and one superficial to the sternocleidomastoid (SCM) muscle to invest the muscle. These layers join into one layer after passing the muscle.

\section{Muscles}

The platysma can be divided into three parts. The prominent posterior pars modiolaris platysma lies posterolateral to the depressor anguli oris. It pulls the corner of the mouth outward and downward. An intermediate pars labialis platysma runs deep into the depressor anguli oris. It acts as a direct vertically downward lower lip tractor. An anterior pars mandibularis platysma attaches to the central mandible and crisscrosses the chin, extending into

\section{Fig. 1. The layers of the neck}

F, frontalis; Te, temporalis; $Z$, zygomatic arch; $P$, parotid gland; $T r$, trapezius; $V$, vessel; $N$, nerve; $M$, mylohyoid muscle; $D$, anterior digastric muscle; SCM, sternocleidomastoid; SMAS, superficial muscular aponeurotic system.

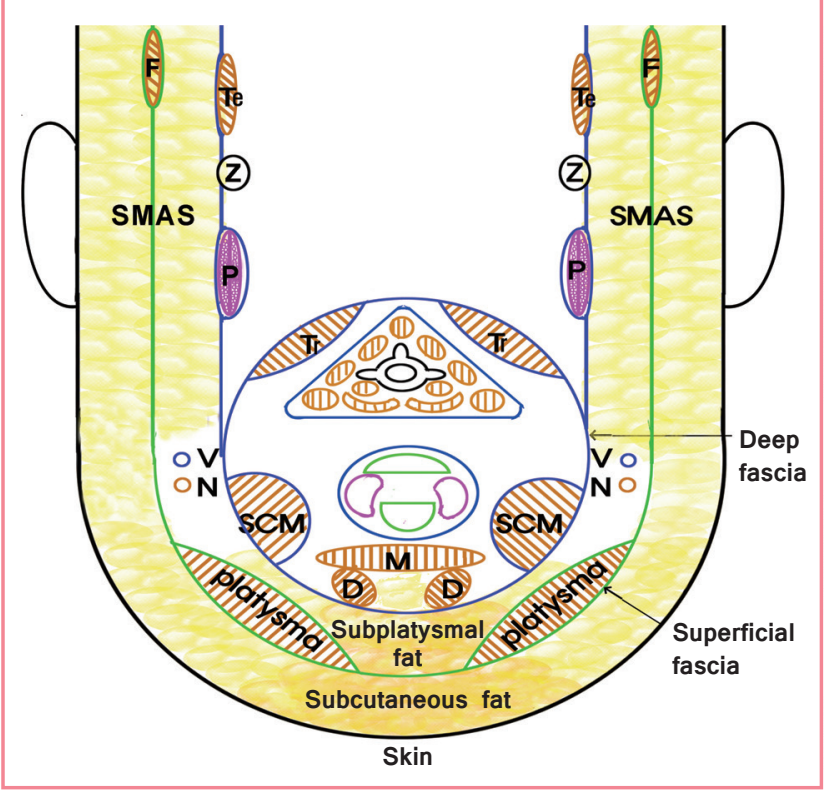


the lower lip [31].

The subplatysmal fat is located below the superficial cervical fascia and is homologous to the sub-SMAS fat, suborbicularis oculi fat, retro-orbicularis oculi fat, and subgaleal fat in the forehead. It is located at the midline between the medial borders of the platysma muscle and extends below the medial border; therefore, it is sometimes called the interplatysmal fat or midline subplatysmal fat. In most cases, it extends to the medial border of the submandibular gland, but in some cases, it may extend below the lateral border of the platysma border to the suprasternal notch.

The anterior digastric muscle originates from the digastric fossa of the mandible and inserts as a ligament to the body and greater horn of the hyoid bone, where it is attached to the posterior digastric muscle. After the removal of the subplatysmal fat, the anterior digastric muscle can be seen below the investing cervical fascia, but sometimes, it is not covered by the fascia. The major functions include elevation of the hyoid bone and swallowing of food.

\section{Motor nerves}

The marginal mandibular branch exits the parotid gland $1 \mathrm{~cm}$ inferior to the mandible border and runs below the platysma muscle. Posterior to the facial vein, it runs superior to the mandible border in $80 \%$ of cases but runs $1-4 \mathrm{~cm}$ below the mandible border in $20 \%$ of cases. Anterior to the facial vein, all small branches run superior to the mandible border and exit the investing cervical fascia $2 \mathrm{~cm}$ posterior to the labial commissure to innervate the platysma, depressor anguli oris, and depressor labii inferioris muscle from the deep surface, and the mentalis muscle from the superficial surface [27]. Mendelson et al. [32] reported that since the region inferior to the premasseteric space does not contain major facial nerves and is very movable, it is not necessary to extend the SMAS incision below the mandible. Further, if the incision is placed between the area from $30 \mathrm{~mm}$ anterior to the ear to $15 \mathrm{~mm}$ superior to the mandible border, the marginal mandibular branch is safe. In $15 \%$ of cases, the marginal mandibular branch communicates with smaller branches of the cervical branch.

The cervical branch runs to the neck posterior to the mandible angle, and enters the platysma muscle from the deep surface $0.5-2.0 \mathrm{~cm}$ inferior to the mandible border and $2-3 \mathrm{~cm}$ anterior to the posterior border of the muscle.

\section{Sensory nerve (great auricular nerve)}

With the patient's head rotated $45^{\circ}$, if we draw a circle with a 3 $\mathrm{cm}$ radius from the midpoint of the SCM muscle, $6.5 \mathrm{~cm}$ inferior to the bony external auditory canal, the great auricular artery exits from the posterior border of the SCM muscle at a point that meets with the circle, $9 \mathrm{~cm}$ inferior to the external auditory canal. Then, it runs straight towards the mandible angle $0.5 \mathrm{~cm}$ posterior to the external jugular vein [33].

\section{Retaining ligaments}

The retaining ligaments and filament structures of the neck are not as strong or distinguished as the face because the bone is less developed and the range of motion in the horizontal direction is large. The three ligaments that fixate the platysma muscle to deeper tissues are the hyoid ligament, paramedian platysmalretaining ligament, and submandibular platysma-retaining ligament [31].

\section{Submandibular gland}

The submandibular gland is located in the triangle that is formed by the lower border of the mandible, the anterior digastric muscle, and the stylohyoid muscle. The gland is covered by the deep investing fascia and has a $\mathrm{C}$-shape, wrapping around the posterior border of the mylohyoid muscle. It is composed of a larger superficial lobe and a smaller deep lobe. Wharton's duct is approximately $5 \mathrm{~cm}$, and begins running from the deep lobe of the gland, with the hypoglossal nerve. It continues between the mylohyoid muscle and the hyoglossus muscle, superiorly and anteriorly, to the intraoral opening lateral and to the frenulum of the tongue. A bulging below the mandible preoperatively may be due to the protrusion or drooping of the submandibular gland, or it may be that the gland is conspicuous because of an eccentric location. It is more easily seen in older patients, but it is also frequently seen in patients in their 20 's or 30 's. Sometimes, the gland is inconspicuous preoperatively but becomes prominent after the removal of fat and may become the cause of considerable complaints from the patient.

\section{SURGICAL TECHNIQUES}

\section{Forehead lift}

\section{Incision line and dissection level}

Preoperative design is done with the patient in a sitting position. The incision line is designed individually depending on the patient, but if the forehead is longer than $6 \mathrm{~cm}$, a hairline incision is appropriate. When designing a hairline incision, the incision line should not be a straight line but a zigzag pattern or irregular broken lines along the individual hairline. If the forehead is less than $6 \mathrm{~cm}$ long, a scalp incision is more appropriate. When performing a scalp incision, it is better to place the final scar at least $6 \mathrm{~cm}$ behind the hairline when possible (Fig. 2). The dissection may be done in a subcutaneous plane, a subgaleal plane, or a subperi- 


\section{Fig. 2. The preoperative design of the forehead lift}

The scalp incision line must be placed $6 \mathrm{~cm}$ posteriorly.

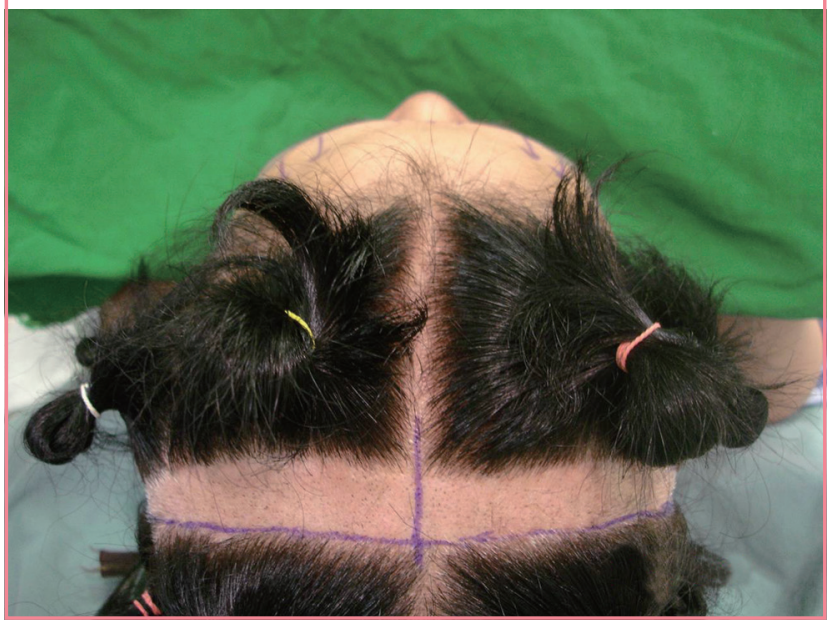

osteal plane. Severe forehead wrinkling requires a subcutaneous dissection, moderate requires a subgaleal dissection, and mild requires a subperiosteal dissection. Severe eyebrow ptosis requires a subperiosteal dissection, moderate requires a subgaleal dissection, and mild requires a subcutaneous dissection.

\section{Procedures}

The surgery is performed under local anesthesia after intravenous anesthesia. After intravenous anesthesia with $1.5 \mathrm{mg}$ midazolam, $25 \mathrm{mg}$ ketamine, and $60 \mathrm{mg}$ Propofol, $2 \%$ lidocaine with 1:100,000 epinephrine is injected along the planned incision line and the periorbital area. $100-150 \mathrm{~mL}$ of tumescent solution, which is made identical to the ones used for conventional liposuction, is also injected in the region in which the flap is to be elevated. This solution includes $1,000 \mathrm{~mL}$ of normal saline, $20 \mathrm{~mL}$ of $2 \%$ lidocaine, $1 \mathrm{~mL}$ of 1:1,000 epinephrine, and $20 \mathrm{~mL}$ of $8.4 \%$ sodium bicarbonate. It is important to inject the local anesthesia once again to minimize bleeding, and $2 \%$ lidocaine with 1:100,000 epinephrine is injected superficially to constrict the subdermal plexus along the incision line. Finally, diluted local anesthesia is injected in all layers of the scalp to constrict the large vessels. While the surgery is being performed, Propofol is continuously injected intravenously at $100-200 \mathrm{mg} / \mathrm{hr}$ by using an infusion pump. Performing a tumescent rhytidectomy as described here minimizes the intraoperative bleeding, makes dissection easier, reduces the postoperative edema and bruising, and provides postoperative analgesia for a long period of time.

When placing the incision, it is better to tilt the scalpel posteriorly $30^{\circ}$ rather than keeping it parallel to the hair follicles. The dissection is performed to cut just through the supraperiosteal layer to the orbital rim, paying careful attention to not injure the deep branch of the supraorbital nerve. When the dissection reaches the level of the eyebrow, the retaining ligaments in the periorbital region should be detached sufficiently to achieve the elevation of the eyebrow. Then, the supraorbital neurovascular bundle, supratrochlear nerve, corrugator, depressor supercilii, and the nasal root are exposed carefully, and the corrugator and procerus muscles are removed partially. In the case of crow's feet, an incision of the orbicularis oculi muscle is performed using an electric knife, and if forehead wrinkling is severe, the frontalis muscle is incised or excised. To allow better adhesion of the elevated flap to the bed, areolar tissue and parts of the frontal periosteum are removed, and excess flap is excised. When excising the excess flap, the scalpel should be tilted $15^{\circ}$ anteriorly, in contrast to the direction of the previous incision, and parallel to the hair shaft so that the hair follicles and papillae are not damaged. The use of this method, enables the postoperative hair growth over the incision scar to help hide the scar. Scalp incisions are closed in one layer using skin staplers. When closing the hairline incision, subcutaneous and skin sutures are performed with 5-0 and 3-0 polydioxanone and 6-0 nylon, respectively [6].

\section{Midface lift}

\section{Incision line and dissection area}

It is important to determine the incision site, as this is easily evaluated by the patients postoperatively. In the temporal area, the $3 \mathrm{~cm}$ incision should be placed horizontally to the highest level of the hairline arch superiorly to the helix; therefore, even if the sideburn is moved superoposteriorly, the hairline arch is maintained. In the preauricular area, a marginal tragal incision is made, and it is crucial to not place the incision as a single curved line, but more like a W-plasty pattern [5]. In the postauricular area, the incision should be placed $4-5 \mathrm{~mm}$ superior to the sulcus, and the occipital incision should be placed as high as possible, making a right angle with the chin line (Fig. 3). The extent of the subcutaneous dissection should be determined, depending on the problem of the patient. In patients with thick skin, it is not necessary to perform extensive subcutaneous dissection to eliminate the perioral wrinkles since the pulling forces from the ear region are delivered sufficiently to the mouth region. However, in patients with thin skin, more dissection around the mouth is necessary to deliver the force vector. In contrast, to surgically correct drooping in patients with thick skin, extensive subcutaneous dissection is necessary, but for patients with thin skin, it is not necessary to perform extensive subcutaneous dissection to effectively lift the face. For the pulling forces to be delivered through the SMAS layer, dissection should always be performed beyond the retaining ligaments [5]. Thick facial skin with drooping as the main problem requires wide skin undermining and SMAS undermining extended beyond the retaining ligaments. In other 


\section{Fig. 3. The preoperative design of the face lift}

The temporal incision is placed within the hairline, perpendicular to the vector of the vertical lift of the face. The incision line around the ear is placed parallel to the helix, drawing a W pattern at the margins of the tragus, and inferiorly following the margins of the earlobe. The postauricular incision is placed $5 \mathrm{~mm}$ above the conchal groove and is extended into the occipital area.

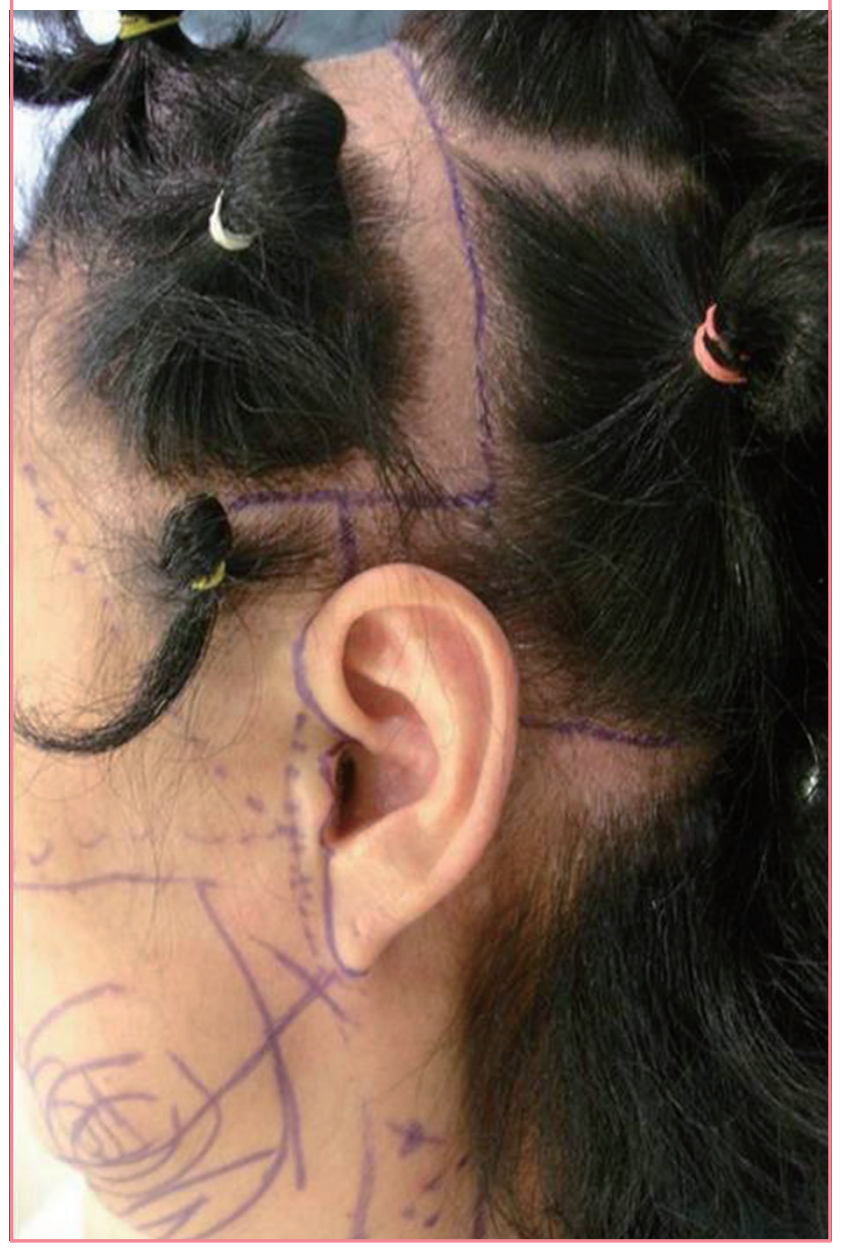

words, thick facial skin with wrinkling as the main problem requires narrow skin undermining and extended SMAS dissection. Thin facial skin with drooping as the main problem requires narrow skin undermining and extended SMAS dissection. Irrespective of whether the skin is thick or thin, if the main problem is volume loss, fat injection is required.

\section{Procedures}

After performing intravenous anesthesia with $1.5 \mathrm{mg}$ midazolam, $25 \mathrm{mg}$ ketamine, and $60 \mathrm{mg}$ Propofol, $300-400 \mathrm{~mL}$ of tumescent solution is injected extensively and the problems of the neck are addressed first. If there is no platysmal band but a double chin from fat deposition, liposuction is performed by a tiny $0.3 \mathrm{~cm}$ incision. It is important to retain some of the subcutaneous fat because a considerable amount of liposuction may make the patient look even older. If there is a platysmal band, then a $2-3 \mathrm{~cm}$ submental incision is placed on the submental crease and the skin flap is elevated. Then, the platysmal flaps are elevated bilaterally from the medial border of the platysma muscle. Excessive muscle is removed, and the platysma muscles are gathered medially and closed with a 4-0 nylon intermittently quilting suture to the bed. The suture extends from the mentum to the superior aspect of the thyroid cartilage or to the base of the thyroid cartilage. If the cervicomental angle is too obtuse, corset platysmoplasty is performed, consisting of subplatysmal fat removal, removal of a part of the anterior digastric muscle, and suture of the medial borders of the platysma muscle at the midline in the lower neck. If the submandibular gland is significantly large or droops down, the platysma muscle in this region is tightened and pushed upwards, or a part of the submandibular gland is removed $[34,35]$.

The incision is placed on the pre-designed facial incision line with a no. 15 blade, and dissection is performed inferomedially from the temporal region and extends to the neck and postauricular region. After sufficient skin dissection is done, hemostasis is achieved using an electrocoagulator. In particular, the transverse facial perforating artery and the submental perforating artery must be coagulated. After hemostasis is achieved, excess fat from the nasolabial fold, jowl, and the double chin region is removed appropriately. The SMAS design for elevating the SMAS flap should be tailored individually for each patient according to the degree of drooping. If the patient is young and the problem lies in the drooping of the nasolabial fold and cheek, a horizontal line parallel to the zygomatic arch is drawn $2 \mathrm{~cm}$ inferior to the zygomatic arch, which moves upwards by $45^{\circ}$, parallel to the nasolabial fold as it goes medially. The vertical line is designed $3 \mathrm{~cm}$ anterior to the ear lobule in a downward direction. If the patient is older with jowls or drooping of the neckline, this vertical line is extended to the inferior mandible border and turned $90^{\circ}$ to the posterior direction and extended. If the patient is even older and platysmal laxity is present, the incision is turned $90^{\circ}$ in the inferior direction and extended to complete the design (Fig. 4). After the design is completed, $20-30 \mathrm{~mL}$ of tumescent solution is injected below the SMAS layer. Incisions are placed along the pre-designed lines using a no. 15 blade, and dissection of the SMAS flap is performed using Metzenbaum scissors beyond the zygomatic ligament. There are anatomic variations in this region of the zygomatic ligament, and in 5\% of the cases, the zygomatic branch of the facial nerve does not run below the deep fascia but rather passes through it to run below the SMAS layer. Hence, in this region, it is sometimes difficult to separate the facial nerve from the zygomatic ligament or the masseteric ligament. Therefore, attentive measures must be taken while cutting the retain- 


\section{Fig. 4. Design for extended SMAS dissection}

(A) The horizontal portion of superficial muscular aponeurotic system (SMAS) dissection begins $1 \mathrm{~cm}$ caudal to the zygomatic arch. The incision is then angled superiorly, parallel to the nasolabial fold. The vertical incision begins $3 \mathrm{~cm}$ anterior to the ear lobe and extends downwards. (B) If the patient has a submental problem, the vertical incision line should extend to a point $2 \mathrm{~cm}$ below the mandibular border and continue posteriorly making a $90^{\circ}$ turn. (C) If the patient has platysmal laxity, the vertical incision line should extend inferiorly along the lateral border of the platysma muscle.
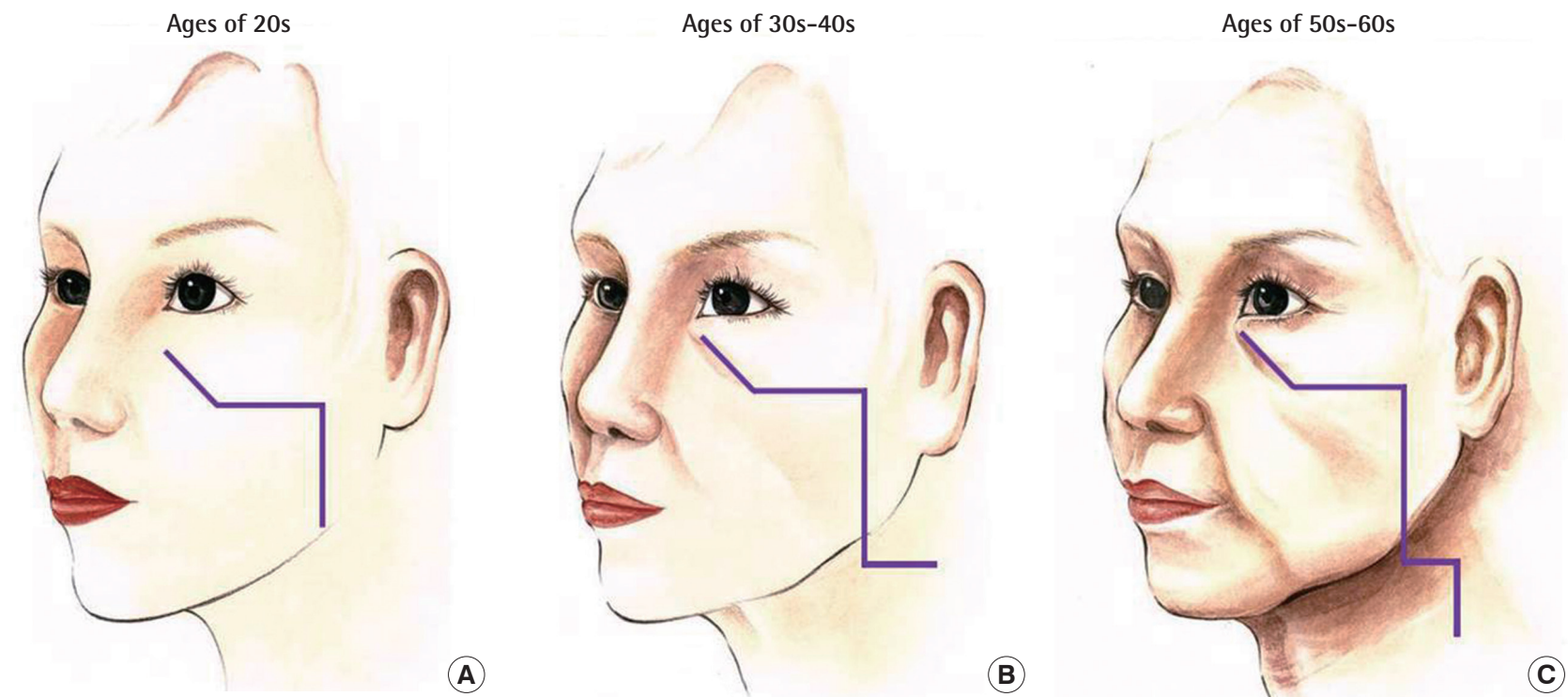

Fig. 5. Elevated extended SMAS facelift flap

(A) The horizontal portion of the superficial muscular aponeurotic system (SMAS) dissection begins $1 \mathrm{~cm}$ caudal to the zygomatic arch. The incision is then angled superiorly, which is parallel to the nasolabial fold. (B) Elevated SMAS flap anterior to the zygomatic and the masseteric ligaments permits excellent mobility of the tissue lateral to the mouth and the nasolabial fold. (C) Transverse facial perforating artery (TA), the submental perforating artery $(\mathrm{SA})$, the retaining ligament $(\mathrm{RL})$, and the facial nerve (FN) (Reproduced form Park DM. Korean J Cosmet Dermatol 2009;6:17-27 [6]).
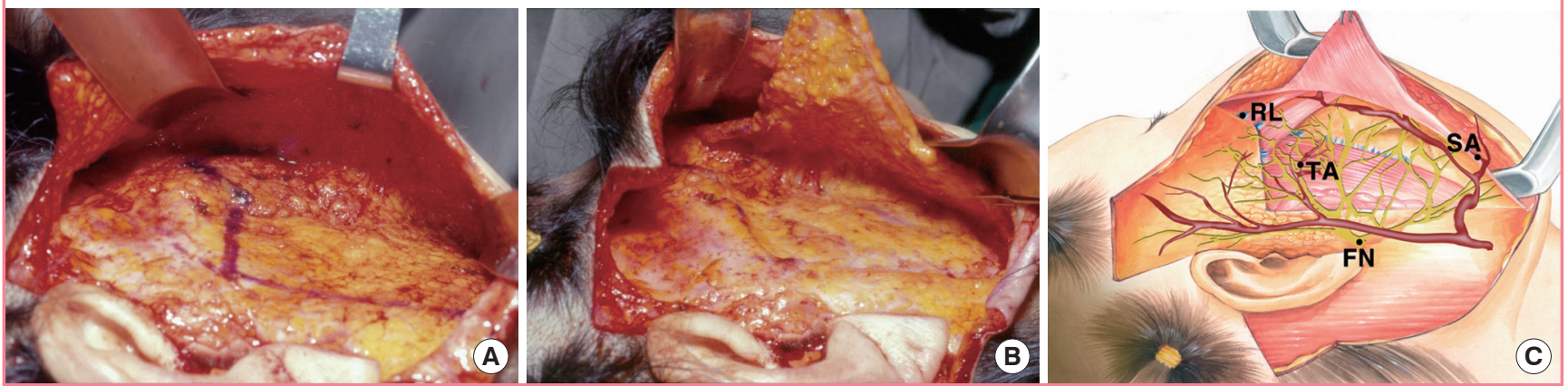

ing ligaments in this region. When the retaining ligament is cut, the SMAS flap becomes more mobile and is easier to displace when pulled upwards. When the delivery of the pulling force is seen at the nasolabial fold upon the pulling of the SMAS flap, dissection is not carried on further (Fig. 5).

To improve the jowl, the zygomatic and masseteric ligaments, as well as the mandibular ligament, have to be cut. The SMAS flap of the neck should be elevated from the tail of the parotid gland, and dissection should be performed sufficiently so that the pulling of the flap allows youthful contours of the mandible border and the submental region. If the jowl is corrected by pull- ing on the SMAS flap, either the SMAS flap is folded or excised, or a transposition flap is created to pull the flap to the postauricular region to be fixated.

The direction of SMAS pulling should be $90^{\circ}$ to the nasolabial fold to correct deep nasolabial folds, and towards the cephaloposterior direction to improve the jowl. A transposition flap should be created and fixated to the mastoid fascia to improve the neckline. The pulling of the skin flap should be mainly in the posterior direction to prevent a change in the direction of the hairline. After a drain is inserted in the occipital region, the scalp is closed using skin staplers in the subcutaneous layer by using 
5-0 nylon and 5-0 polydioxanone, and in the skin by using 6-0 nylon [5].

\section{Neck lift}

Incision line and dissection area

The incision line and range of dissection is marked according to the individual patient in a sitting position. If the aging changes are mild and there are no problems in the midline neck or submental area, a periauricular incision is sufficient. If there are severe aging changes, or if there is a platysmal band or blunting of the cervicomental angle, a submental incision is added.

\section{Procedures}

After the design is done, the patient is laid supine on the operation table. Injection of intravenous anesthetic agents $(1.5 \mathrm{mg}$ of midazolam, $25 \mathrm{mg}$ of ketamine, and $60 \mathrm{mg}$ of Propofol) is followed by the injection of tumescent solution in the region in which the skin flap is to be elevated. The $2.5-$ to $3.5-\mathrm{cm}$ submental incision is placed on the submental crease, or $5 \mathrm{~mm}$ superior or inferior to the crease. If there is excess fat in the submental region and it bulges out to cause blunting of the cervicomental angle, liposuction or lipectomy of the subcutaneous fat is done. When elevating the skin flap through the submental incision, a 2 to $3 \mathrm{~mm}$ thick subcutaneous fat pad should be attached below the skin. The flap is elevated laterally as far as possible, possibly beyond the SCM muscle, superiorly to the mid-portion of the mandible body, and inferiorly at least to the suprasternal notch past the thyroid and cricoid cartilages. After the skin flap is elevated, the fat attached to the surface of the platysma muscle is removed. The subcutaneous fat on the medial bands of the bilateral platysma muscles and the fat covering the superficial cervical fascia, which connects the medial borders of the platysma muscle, are removed using a pair of Metzenbaum scissors in an inferior direction. Fat removal should not extend to the thyroid cartilage, and the fat covering the thyroid cartilage should be left intact to prevent a masculine appearance due to the protrusion of the cartilage. If platysma muscles of both sides interdigitate at the midline in the submental area, the muscle and the fascia are removed in a band-like manner through the midline to reveal the underlying subplatysmal fat. Both medial borders of the platysma muscles are elevated, and the subplatysmal fat is removed. Then, the anterior belly of the digastric muscle can be observed in the submental triangle, below the investing cervical fascia. After the removal of the fat, the neck is flexed to see if any bulging remains, and if there is bulging, interdigastric fat is removed, and the $70 \%$ to $90 \%$ of the anterior belly of the digastric muscle is partially excised using the electric knife [35]. The platysma muscles are gathered medially and closed with 4-0 nylon

\section{Fig. 6. Elevated medial border of the platysma muscle}

The platysma muscles are gathered medially and closed with a 4-0 nylon intermittently quilting suture to the bed. The suture extends from the mentum to the superior aspect of the thyroid cartilage or to the base of the thyroid cartilage (Reproduced form Park DM. Korean J Cosmet Dermatol 2009;6:17-27 [6]).

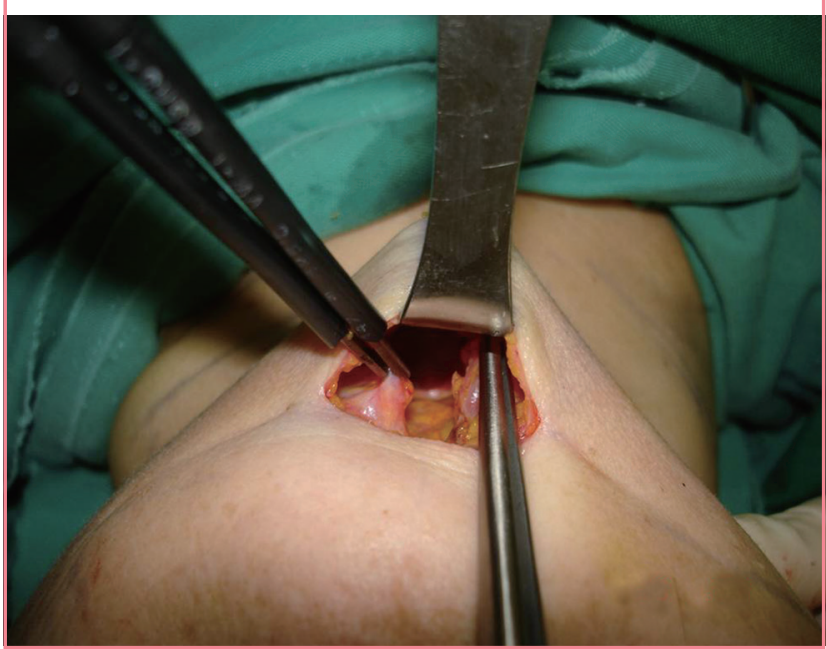

intermittently quilting sutures to the bed. Continuous sutures are used in the inferior direction, and even though closure to the suprasternal notch may not be possible, closure should be done at least to the cricoid cartilage. Then, additional sutures are performed to gather bilateral muscles more laterally to the previous sutures at the midline, in an ascending direction, making the platysma muscle hard and smooth. When the sutures return to the submental region and the platysma is well tightened, the suture is tied (Fig. 6).

After the platysmaplasty is finished, a skin incision is placed from the postauricular region to the occipital region by using a no. 15 blade. In the postauricular region, the incision is placed 4-5 $\mathrm{mm}$ in the direction of the concha from the auriculocephalic sulcus, to the level of the antihelix so that the incision is well hidden, and then turned horizontally parallel to the mandible and extended to the occipital region. The length of the horizontal incision is determined when there is no dog-ear formation upon the posterosuperior fixation of the skin flap. When the skin on the mastoid process is elevated through the postauricular incision, the skin is adhered tightly to the mastoid process; therefore, it is necessary to elevate the flap just over the investing deep fascia and not too thinly. Further, care should be taken not to damage the great auricular nerve, which is located over the SCM muscle, $6.5 \mathrm{~cm}$ inferior to the external auditory meatus [33], and the SCM fascia should not be penetrated as the nerve is easily injured [31]. After passing the great auricular nerve while elevating the flap inferiorly, the platysma muscle is encountered. The skin flap is elevated over the platysma muscle 
via a supraplatysmal dissection, and this space is connected to the space created during the platysmaplasty. After the elevation of the skin flap, hemostasis should be achieved, and care must be taken to cauterize the submental perforating artery, which is located at the midpoint between the menton and the gonion. To elevate the platysma muscle flap from the posterior side, the lateral border of the platysma is held with one hand, $5 \mathrm{~cm}$ inferior to the mandible angle. Special attention must be paid to not damage the external jugular vein or the great auricular nerve [36]. If the platysma muscle is very lax, subplatysmal dissection is performed through the posterior border of the muscle (Fig. 7). Then, the platysma muscle is pulled posteriorly and fixated with sutures. Care must be taken to not include the great auricular nerve with the muscle [21]. After pulling the skin flap

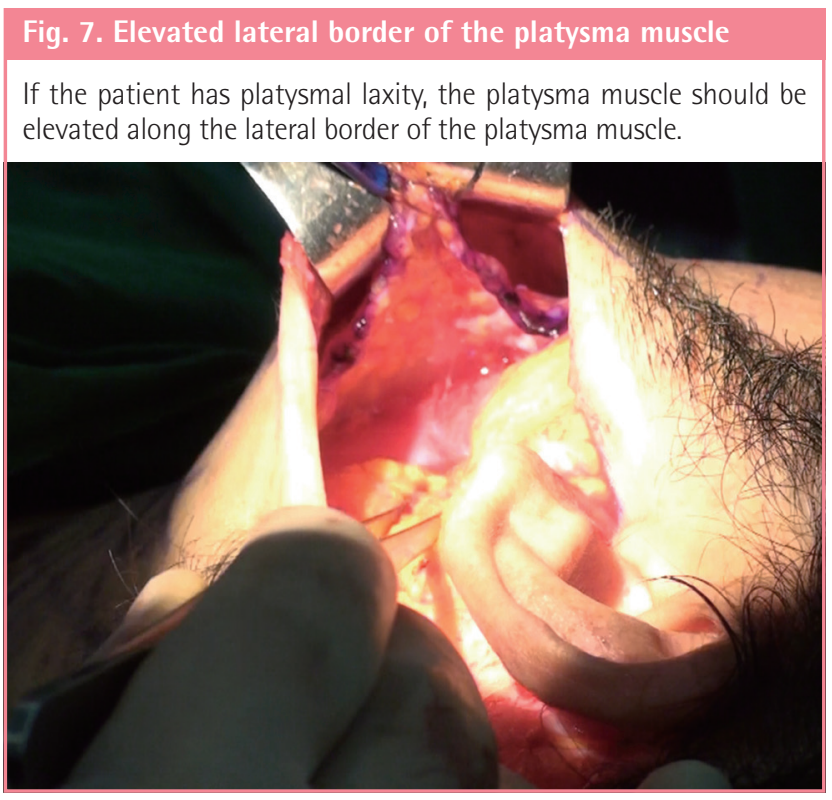

posterosuperiorly, excess skin is excised without a change to the hairline, and a drain is inserted. Then, the scalp is closed using skin staplers in the subcutaneous layer by using 5-0 nylon and 5-0 polydioxanone, and in the skin by using 6-0 nylon [6].

\section{POSTOPERATIVE CARE}

A mild compressive dressing is applied postoperatively, and an ice pack is applied when the patient is admitted in the hospital room for a day. After 24 hours, all the dressing is removed and the patient's hair is washed. Every other staple of the 50-60 staples in the scalp is removed, leaving only 20-30 staples. Finally, the drain is removed and the patient is discharged. The patient is followed up 48 hours postoperatively, and on the fourth postoperative day, all skin sutures are removed. Further, on the seventh postoperative day, all scalp staples are removed. The scar may become more inconspicuous if paper plaster is applied on the incision scars after the removal of sutures. Up to 1 month postoperatively, the scar on the operative site hardens, and the sensory function is not fully recovered; therefore, the application of hot packs on the site should be inhibited as burns sometimes occur. Two to three months after the surgery, the tissues at the operative site become more pliable, and the fat harvested at the time of the surgery is transplanted in places to make the face smoother. Six months after the surgery, all the swelling is gone and the final appearance will be visible (Fig. 8).

\section{COMPLICATIONS}

\section{Pixie ear}

Pixie ears are caused by the downward pulling of the medial

\section{Fig. 8. A case of a total extended SMAS facelift}

A 55-year-old woman before and one year after undergoing a forehead lift, extended superficial muscular aponeurotic system (SMAS) facelift, and neck lift.
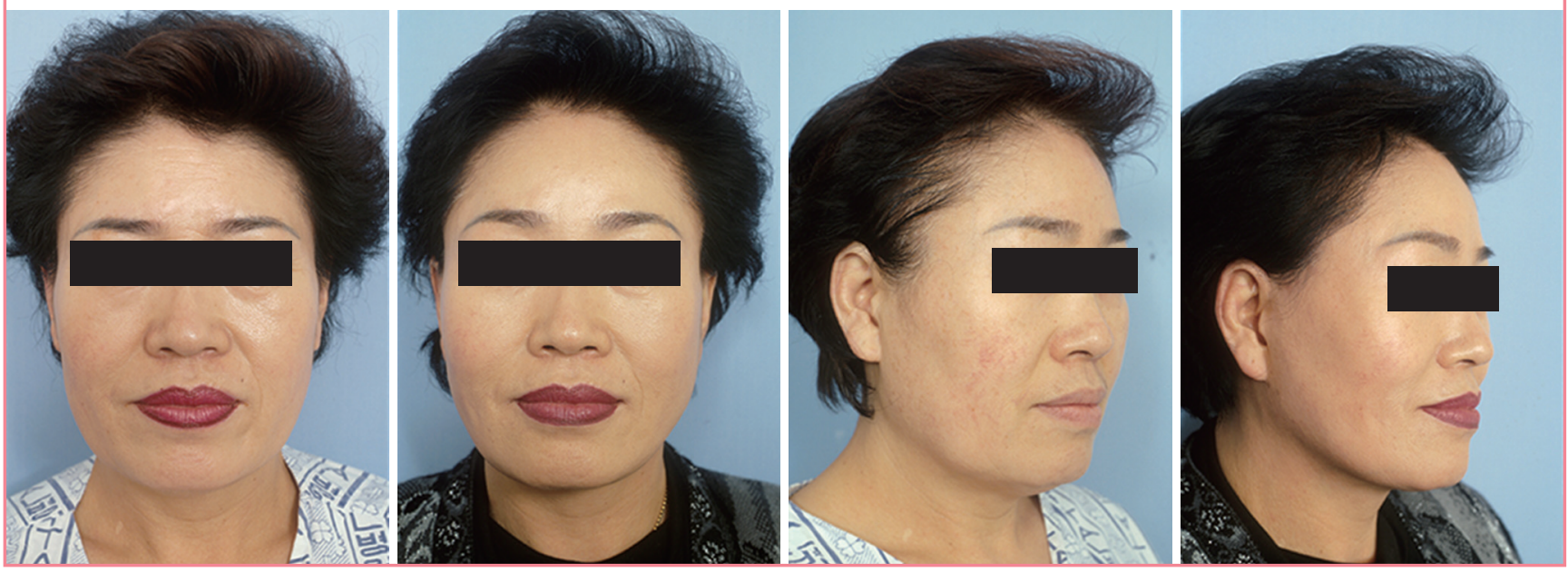
cheek and jawline skin flap, eliminating the free caudal segment and elongating the attached cephalic segment of the ear lobule. This occurs in $5.7 \%$ of cases [37]. To treat this condition, a medially based triangular excision is done, where the length and the width of the triangle to be excised must be equal, creating an equilateral triangle. If the height of the excised segment is 1 $\mathrm{cm}$, the attached cephalic segment decreases by $9 \mathrm{~mm}$ and the free caudal segment increases by $3 \mathrm{~mm}$. To prevent the pixie ear deformity after the facelift, the earlobe soft tissue retaining ligaments in the mastoid region should be detached to the new otobasion inferius level. The fixation to the attached segment should ensure that the length of the attached cephalic segment is less than $15 \mathrm{~mm}$, and the length of the free caudal segment is around $5 \mathrm{~mm}$. The free segment should not be sutured and healed by secondary intention. This method will form a more curved and blunt-edged earlobe, compared to that formed by a free segment suture [37].

\section{Hematoma}

Hematoma is the most common complication after facelifts, occurring in $0.2 \%$ to $8 \%$ of the cases. Most hematomas occur 10 to 12 hours postoperatively. In case of the acute onset of swelling and pain on one side of the face, the wound should be checked for the formation of hematomas. Hypertension is the most common underlying cause of hematomas, and vomiting, coughing, and taking medication such as aspirin may be the cause. When the patient is hypertensive, $5 \mathrm{mg}$ of hydralazine may be injected three times at intervals of 10 minutes; alternatively, a $\beta$-blocker (esmolol hydrochloride, Brevibloc) may be used. If there are blood clots or gelatinization of blood at the operative site, the wound must be opened and the bleeding point must be found and coagulated. If it is left untouched, it may cause skin necrosis [38].

\section{Seroma}

Seroma is the second most common complication after hematomas. It usually forms on one side of the face or at the back of the neck. Repeated needle aspirations are sufficient, and usually last up to $7-10$ days.

\section{Skin necrosis}

Skin necrosis is not common, but it may occur if the elevated flap is too long or thin, the dressing is too tight, or hematomas are left untouched. Burns or cold injuries are caused by the application of hot or cold packs at the paresthetic operative site, and in smokers. Skin necrosis can also occur when previous lacerated scars are overlooked and the flap is elevated extensively. For prevention, the subdermal plexus should be left intact during dissection, and the application of excessive pressure on the dressing should be avoided. Nicotine releases catecholamines and chalone cofactors to hinder epithelization and decrease inflammatory responses. In particular, during 6-10 postoperative days, it has a bad influence on wound healing. Smoking should be prohibited from 10 days before the surgery to 21 days afterwards [39]. In the early phases of skin necrosis, extensive bruising is present, usually along the mandibular line inferior to the earlobe or in the postauricular region. Venous congestion is seen as bruising, and if this condition persists, epidermolysis may occur with blistering and desquamation, which may in turn cause skin sloughing. In case of superficial dermal sloughing, conservative treatment with antibiotic ointment is done to prevent eschar formation, and healing by secondary intention is also commonly done. If skin necrosis occurs, it should not be addressed immediately but rather treated conservatively for 1-2 weeks, and if scarring is excessive, scar revisions should be performed six months later.

\section{Asymmetry}

To prevent asymmetry, accurate preoperative planning and performance of the surgery according to the plan is important. If asymmetry occurs, the skin flap is elevated slightly and the SMAS is trimmed and sutured again to correct the problem.

\section{Nerve injury}

Paresthesia of the parietal regions is common after forehead lifts due to the damage of the deep branch of the supraorbital nerve. Paresthesia of the anterior forehead due to the damage of the superficial branch of the supraorbital nerve usually recovers after a few months postoperatively. In the face, paresthesia of the earlobe due to the damage to the great auricular nerve is most common. Damage to the facial nerves is not very common, but among the various types of damage possible, damage to the temporal branch or the marginal mandibular branch is relatively common, although the motor function is spontaneously recovered within a few months to one year postoperatively in most cases, and permanent palsy occurs in less than $0.1 \%$ of cases [40] The temporal branch divides into anterior, middle, and posterior branches, and the frontal branch (terminal branch of the temporal nerve) exits the parotid at a point $0.5 \mathrm{~cm}$ inferior and $1.5 \mathrm{~cm}$ anterior to the tragus and divides into many small branches in 1 $\mathrm{cm}$ intervals to pass over the zygomatic arch at the midpoint between the radix helicis and lateral canthus. The nerve runs under the temporoparietal fascia, and at the level of the superior orbital rim. It penetrates the undersurface of the frontalis muscle to innervate the muscle. This can also be seen $2-9 \mathrm{~mm}$ superior to the sentinel vein (branch of the internal maxillary vein), which is located lateral to the frontozygomatic suture line. The procerus muscle is innervated by the superior buccal branch (nasal 
extension of the buccal branch) or the lower zygomatic branch, and has no relationship to the frontal branch [41]. The cervical branch exits the parotid gland at the inferior margin and immediately penetrates the deep investing fascia to run superficially between the fibroareolar connective tissue and the platysma muscle. The nerve runs below the platysma muscle before entering the muscle. The platysma muscle is a lip depressor and cofunctions with the depressor anguli oris. It acts when a person makes a full denture smile. Damage to the cervical branch is present in $1.7 \%$ of cases, and is fully recovered after 3 weeks to 6 months. It is important to distinguish between the damage to the cervical branch and the marginal mandibular branch. The damage to the marginal mandibular branch causes the dysfunction of the mentalis muscle as well as the platysma muscle. Thus, in the case of cervical branch injuries, the patient can elevate and protrude the lower lip, but in the case of marginal mandibular nerve injuries, the patient cannot [42].

\section{Alopecia}

The causes of alopecia include hypoxia of hair follicles, inappropriate incisions, and individual differences. Hypoxia of hair follicles may be caused by excessive stretching of the flap, elevation of a thin flap with injury to the vessels supplying the hair follicles, or thermal injury to the hair follicles during hemostasis with an electrocoagulator. The strong and extended clamping applied along the incision line, strangulation or damage to the vessels by the sutures, or the application of excessive pressure on the dressing can also be causes of hypoxia [6]. The direction of the scalpel while placing the incision may affect the amount of cicatricial alopecia postoperatively. Further, people innately more prone to hair loss may have more prominent alopecia postoperatively, regardless of other conditions. Alopecia is usually corrected within 4-6 months with the growth of new hair. If no hair growth is observed after one year, and if the width of the alopecia is less than $1 \mathrm{~cm}$, excision and primary closure may be a solution. If the width of the alopecia is more than $1 \mathrm{~cm}$, hair grafting is more appropriate.

\section{Parotid injury}

If injury to the parotid gland is overlooked during surgery, swelling is seen 5-7 days postoperatively, which increases when eating or can even create a fistula. If a salivary cyst is formed lateral to the buccinator, it is drained to the skin, and if the cyst is medial to the buccinator, it is drained to the oral mucosa. Damage to the parotid gland can be divided into parenchymal injury and ductal injury. Parenchymal injury occurs during the manipulation of the SMAS because the SMAS is adhered to the parotid capsule (deep fascia). The damage is more common on the tail portion, including many terminal ductules, because the parenchyme is relatively thin, leading to salivary leakage. Ductal injury may be caused by a direct cutting of the duct or obstruction of the duct due to excessive stretching of the SMAS. If damage to the parotid parenchyme is observed during the operation, dissection must be stopped to check the damaged part. The damaged gland is electrocauterized to prevent leakage from the ductules, and the capsule and the superficial fascia are closed in a watertight manner. If the duct is cut, a monostent is inserted and the duct is repaired. Moreover, the symptoms of parotid injury can also develop after surgery. In the case of ductal injuries, surgical intervention is the treatment principle, and in the case of parenchymal injuries, conventional treatment may be sufficient to achieve correction in 4-5 weeks [43].

\section{Synkinesis}

After undergoing a facelift, the patient may exhibit synkinesis of multiple facial expression muscles. There are various mechanisms to this phenomenon. The leading explanation for pathogenesis is that axonal regeneration of the damaged nerves is directed in the wrong direction to undesired peripheral muscle targets, creating an abnormal innervation. Another theory states that ineffective myelinization nerve fibers connect to nearby nerve fibers to create undesired neural pathways, and the area receives the wrong nerve signals through these pathways. A third theory states that because the peripheral input is decreased due to axonal degeneration after nerve injuries, hypersensitivity to neurotransmitters may cause undesired, uncoordinated movements. A representative case of this phenomenon is the involuntary contraction of muscles at the corner of the mouth when blinking. This phenomenon commonly occurs after subcutaneous or sub-SMAS dissection near the zygomatic-retaining ligament due to nerve injuries. After exiting the parotid gland, a majority of the facial nerves run below the deep fascia to enter the muscles. However, in some cases, the zygomatic branch penetrates the deep fascia lateral to the zygomaticus major muscle and runs to the medial side to enter the muscle, which increases the risk of nerve injury. The zygomatic branch divides into the superior ramus, which enters the orbicularis oculi muscle, and the inferior ramus, which enters the zygomaticus major and levator anguli oris muscle in this region. Damaged nerves may heal between wrong targets to create synkinesis. For an exact diagnosis, involuntary movement of the muscles at the mouth corner should be observed while telling the patient to blink, involuntary movement of the periorbital muscles should be observed while telling the patient to smile slightly, and finally, the movement of the periorbital muscles should be observed while the patient makes a full smile. To treat this condition, selective neurectomy, 
selective myectomy, and injection of botulinum toxin may be done $[44,45]$.

\section{Other complications}

Hypertrophic scarring and infection may occur postoperatively.

\section{DISCUSSION}

Aging is caused by many factors. Excess sun exposure, smoking, or drinking may significantly age a person. Research suggests that smoking for 10 years ages a person by 2.5 years [46].

In performing a forehead lift, the dissection plane is determined by the problem that the patient has. Troilius [47] has reported that after a subgaleal bicoronal brow lift, the brow level returns to the preoperative level after 5 years, and if an upper blepharoplasty is performed concomitantly, the brow droops below the original level. Thus, he moved on from this procedure to an endoscopic subperiosteal brow lift. This procedure maintained approximately $2.5 \mathrm{~mm}$ of the brow position elevation after 5 years. This phenomenon is due to a change in the dynamic balance of the eyebrows and also due to the loss of the negative vector of the corrugator, procerus, and depressor supercilii muscles. The antagonist frontalis muscle contracts slowly to lift the brow upwards; hence, no additional fixation is necessary in the case of the endoscopic subperiosteal brow lift. Further, he reported that if an upper blepharoplasty is performed concomitantly in an endoscopic subperiosteal brow lift, as opposed to the subgaleal bicoronal brow lift, the brow does not droop down to the original level and there are minimal changes in the results [47].

Ramirez reported that in determining the long-term results, whether or not the frontalis muscle was manipulated is more significant than the plane of dissection. The elevation of the brow after the surgery occurs to compensate for the weakening ptosis of the levator palpebrae superioris [47].

To recapitulate, the most important factor of a forehead lift is the manipulation of muscles, rather than the site of incision or the plane of dissection. In short, there are elevator and depressor muscles balanced around the eyebrows on the forehead. How the strengths of these muscles are reduced and altered determine the result and longevity of the operation.

To shorten a slightly tall forehead, a hairline incision with subcutaneous or subgaleal plane dissection should be done to perform a brow lift, and excess skin can be excised. In the case of an extremely long forehead, pretrichial incision and extensive dissection to the occipital area should be done, and relaxation incisions should be made to lengthen the flap. Then, the flap is pulled forward and the galeal fascia is fixed using the bone tunneling technique with 3-0 PDS. Subcutaneous dissection is addi- tionally performed in the anterior direction to release the fibrous bands that create horizontal wrinkles, and finally, the corrugator is removed through a cut to the frontalis muscle [48].

The prezygomatic space is superior to the zygoma body; the upper border is the retaining ligaments of the eyelid and cheek, the lower border covers the superior origins of the zygomaticus major/minor and the levator labii superioris muscle. The lateral portions reach the posterior border of the zygoma, and there are no facial nerves passing through this space, only the zygomaticofacial nerve. To dissect through the sub-SMAS space in the lower cheek at the prezygomatic space, the prezygomatic membrane and zygomatic ligaments have to be cut [49]. The premasseteric space overlies the lower half of the masseter. The posterior border is defined by the platysma auricular fascia, and the anterior border is reinforced by the masseteric ligament and the mandibular ligament. The inferior border has no ligamentous support and is located approximately $15 \mathrm{~mm}$ superior to the angle of the mandible. The superior border is the upper edge of the platysma [32]. The space between the prezygomatic space and the premasseter space is known as the middle premasseter space. Below the floor of this space run the parotid duct and the upper and lower buccal trunks [50]. Some branches of the marginal mandibular branch pass over the premasseter space. The nerve passes over the masseter muscle anteriorly, $8 \mathrm{~mm}$ superior to the mandible angle. One branch runs below this space floor and another branch over this space, to the lower platysma muscle [32]. When placing a preauricular SMAS incision to dissect the SMAS layer, there is a risk of causing damage to the mandibular branch; this can be prevented by placing the incision $30 \mathrm{~mm}$ anterior to the ear.

Jowl fat is different from buccal fat and is composed of two subcutaneous compartments at the mandible border, which are the superior and inferior jowl compartments. The jowl fat is separated from the submandibular fat by the mandibular septum. The mandibular septum interdigitates with fibers from the platysma muscle to attach to the mandible anterior border, fixating the skin to the mandible border. This is why the skin at the mandible border is mobile in the superior direction, but not as much in the inferior direction [51]. Furnas [52] reported in 1989 on the dense adhesions (mandibular ligament) located at the anterior $1 / 3$ of the mandible border, but did not mention the adherence present in the middle $1 / 3$. Only a few researchers reported that jowls are secondary changes caused by volume loss, and Yousif [53] reported that they are caused by the drooping of the soft tissue due to gravitational forces and tissue laxity.

The normal size of the ear lobule is thought to be $20 \mathrm{~mm}$ [54, 55], and if it is larger, it may be seen as a sign of aging. McKinney reported the average length of the ear lobule and the ear to be 18 
$\mathrm{mm}$ and $65 \mathrm{~mm}$, respectively. The ratio of the length of the ear lobule to that of the ear is 28 , and this ratio increases with aging. The normal range for the ear lobule to ear ratio is $25-30$, and if it exceeds 33, a reduction of the ear lobule is recommended. A more natural-looking appearance may be obtained if the dermal layer at the base of the tragal flap is fixed to the underlying fascia or cartilage. Perform 2-3 anchoring sutures with 5-0 Prolene to create a depression at the pretragal portion $[56]$.

\section{CONCLUSIONS}

While general aesthetic plastic surgery is performed to change a person's innate looks, rejuvenation surgeries are performed to fix the problems caused by aging, returning a patient to a younger state. The problems that appear on the face due to aging include wrinkles, blemishes, age spots, volume loss, and sagging of tissues. When seen close up, wrinkles are the major cause of appearing old, while from far away, volume loss and the drooping of tissues are the major causes. Wrinkles start to form in the late 20s at places with the thinnest skin, such as the periorbital area, and as people grow older, volume loss and the drooping of tissue begin. These problems cannot be addressed with a single procedure. To address the problem of wrinkles or volume loss, relatively simple procedures such as botox, fillers, and fat injections may be sufficient, but to rejuvenate a sagging face, facelifts need to be performed.

Surgical methods such as non-invasive or minimally invasive facelifts may have a shorter recovery period, but the effects are only temporary. Despite the slightly longer recovery periods, conventional facelifts should be performed to obtain predictable outcomes, to maximize the efficiency of surgery, and to maintain the long-lasting effects.

\section{REFERENCES}

1. Lemperle G, Holmes RE, Cohen SR, et al. A classification of facial wrinkles. Plast Reconstr Surg 2001;108:1735-50.

2. Lovell CR, Smolenski KA, Duance VC, et al. Type I and III collagen content and fibre distribution in normal human skin during ageing. Br J Dermatol 1987;117:419-28.

3. Branchet MC, Boisnic S, Frances C, et al. Skin thickness changes in normal aging skin. Gerontology 1990;36:28-35.

4. Kligman LH. Photoaging. Manifestations, prevention, and treatment. Dermatol Clin 1986;4:517-28.

5. Park DM. Extended SMAS Facelift. J Korean Soc Aesthetic Plast Surg 2007;13:167-74.

6. Park DM. Full facelift. Korean J Cosmet Dermatol 2009;6: 17-27.
7. Chajchir A, Benzaquen I. Liposuction fat grafts in face wrinkles and hemifacial atrophy. Aesthetic Plast Surg 1986;10: 115-7.

8. Coleman SR. Long-term survival of fat transplants: controlled demonstrations. Aesthetic Plast Surg 1995;19:421-5.

9. Hollander E. Pastische operration: dritische darstellung ihres gegenwartigen standes. In: Klemperer G, Klemperer F, editors. Neue Deutsche Klinik. Vol. 9. Berlin: Urban \& Schwarzenberg; 1932. p.1-17.

10. Mitz V, Peyronie M. The superficial musculo-aponeurotic system (SMAS) in the parotid and cheek area. Plast Reconstr Surg 1976;58:80-8.

11. Psillakis JM, Rumley TO, Camargos A. Subperiosteal approach as an improved concept for correction of the aging face. Plast Reconstr Surg 1988;82:383-94.

12. Hamra ST. The deep-plane rhytidectomy. Plast Reconstr Surg 1990;86:53-61.

13. Hamra ST. Composite rhytidectomy. Plast Reconstr Surg 1992;90:1-13.

14. Stuzin JM, Baker TJ, Gordon HL. The relationship of the superficial and deep facial fascias: relevance to rhytidectomy and aging. Plast Reconstr Surg 1992;89:441-9.

15. Mendelson BC. Correction of the nasolabial fold: extended SMAS dissection with periosteal fixation. Plast Reconstr Surg 1992;89:822-33.

16. Tonnard P, Verpaele A, Monstrey S, et al. Minimal access cranial suspension lift: a modified S-lift. Plast Reconstr Surg 2002;109:2074-86.

17. Rondo Junior W, Vidarte G, Michalany N. Histologic study of the skin with gold thread implantation. Plast Reconstr Surg 1996;97:256-8.

18. Saylan Z. The S-lift: less is more. Aesth Surg J 1999;19:4069.

19. Baker DC. Minimal incision rhytidectomy (short scar face lift) with lateral SMASectomy: evolution and application. Aesthet Surg J 2001;21:14-26.

20. Knize DM. A study of the supraorbital nerve. Plast Reconstr Surg 1995;96:564-9.

21. Seckel BR. Facial danger zones: avoiding nerve injury in facial plastic surgery. St. Louis, MO: Quality Med Publish; 1994.

22. Furnas DW. Landmarks for the trunk and the temporofacial division of the facial nerve. Br J Surg 1965;52:694-6.

23. Moss CJ, Mendelson BC, Taylor GI. Surgical anatomy of the ligamentous attachments in the temple and periorbital regions. Plast Reconstr Surg 2000;105:1475-90.

24. Stuzin JM, Baker TJ, Gordon HL, et al. Extended SMAS dissection as an approach to midface rejuvenation. Clin 
Plast Surg 1995;22:295-311.

25. Jost $G$, Levet $Y$. Parotid fascia and face lifting: a critical evaluation of the SMAS concept. Plast Reconstr Surg 1984;74: 42-51.

26. Barton FE Jr. The SMAS and the nasolabial fold. Plast Reconstr Surg 1992;89:1054-7.

27. Freilinger G, Gruber H, Happak W, et al. Surgical anatomy of the mimic muscle system and the facial nerve: importance for reconstructive and aesthetic surgery. Plast Reconstr Surg 1987;80:686-90.

28. Gosain AK. Surgical anatomy of the facial nerve. Clin Plast Surg 1995;22:241-51.

29. Alghoul M, Bitik O, McBride J, et al. Relationship of the zygomatic facial nerve to the retaining ligaments of the face: the Sub-SMAS danger zone. Plast Reconstr Surg 2013;131: 245e-252e.

30. Roberts TL 3rd, Pozner JN, Ritter E. The RSVP facelift: a highly vascular flap permitting safe, simultaneous, comprehensive facial rejuvenation in one operative setting. Aesthetic Plast Surg 2000;24:313-22.

31. Feldman JJ. Surgical anatomy of the neck. In: Feldman JJ, editor. Neck lift. St. Louis, MO: Quality Medical Pub; 2006. p.73-152.

32. Mendelson BC, Freeman ME, Wu W, et al. Surgical anatomy of the lower face: the premasseter space, the jowl, and the labiomandibular fold. Aesthetic Plast Surg 2008;32:18595.

33. McKinney P, Katrana DJ. Prevention of injury to the great auricular nerve during rhytidectomy. Plast Reconstr Surg 1980;66:675-9.

34. Connell BF, Hosn W. Importance of the digastric muscle in cervical contouring: an update. Aesth Surg J 2000;20:12-6.

35. Connell BF. Male face lift. Aesthet Surg J 2002;22:385-96.

36. Kang JS. Plastic surgery. 3rd ed. Seoul: Koonja Pub.; 2004.

37. Mowlavi A, Zakhireh M. Avoiding the "pixie-ear" deformity following face lift surgery by differential insetting and secondary intention healing. Aesthet Surg J 2005;25:467-70.

38. Baker DC, Chiu ES. Bedside treatment of early acute rhytidectomy hematomas. Plast Reconstr Surg 2005;115:2119-22.

39. Adamson PA, Moran ML. Complications of cervical rhytidectomy. Facial Plast Surg Clin North Am 1993;1:257.

40. Matarasso A, Elkwood A, Rankin M, et al. National plastic surgery survey: face lift techniques and complications. Plast Reconstr Surg 2000;106:1185-95.

41. Moody FP, Losken A, Bostwick J 3rd, et al. Endoscopic frontal branch neurectomy, corrugator myectomy, and brow lift for forehead asymmetry after facial nerve palsy. Plast Reconstr Surg 2001;108:218-23.

42. Daane SP, Owsley JQ. Incidence of cervical branch injury with "marginal mandibular nerve pseudo-paralysis" in patients undergoing face lift. Plast Reconstr Surg 2003;111: 2414-8.

43. Barron R, Margulis A, Icekson M, et al. Iatrogenic parotid sialocele following rhytidectomy: diagnosis and treatment. Plast Reconstr Surg 2001;108:1782-4.

44. Guerrissi JO. Selective myectomy for postparetic facial synkinesis. Plast Reconstr Surg 1991;87:459-66.

45. Terzis JK, Karypidis D. Therapeutic strategies in post-facial paralysis synkinesis in adult patients. Plast Reconstr Surg 2012;129:925e-939e.

46. Guyuron B, Rowe DJ, Weinfeld AB, et al. Factors contributing to the facial aging of identical twins. Plast Reconstr Surg 2009;123:1321-31.

47. Troilius C. Subperiosteal brow lifts without fixation. Plast Reconstr Surg 2004;114:1595-603.

48. Guyuron B, Behmand RA, Green R. Shortening of the long forehead. Plast Reconstr Surg 1999;103:218-23.

49. Mendelson BC, Muzaffar AR, Adams WP Jr. Surgical anatomy of the midcheek and malar mounds. Plast Reconstr Surg 2002;110:885-96.

50. Mendelson $\mathrm{BC}$, Wong $\mathrm{CH}$. Surgical anatomy of the middle premasseter space and its application in sub-SMAS face lift surgery. Plast Reconstr Surg 2013;132:57-64.

51. Reece EM, Pessa JE, Rohrich RJ. The mandibular septum: anatomical observations of the jowls in aging-implications for facial rejuvenation. Plast Reconstr Surg 2008;121:1414 20.

52. Furnas DW. The retaining ligaments of the cheek. Plast Reconstr Surg 1989;83:11-6.

53. Yousif NJ. Changes of the midface with age. Clin Plast Surg 1995;22:213-26.

54. Rubin LR, Bromberg BE, Walden RH, et al. An anatomic approach to the obtrusive ear. Plast Reconstr Surg Transplant Bull 1962;29:360-70.

55. Loeb R. Earlobe tailoring during facial rhytidoplasties. Plast Reconstr Surg 1972;49:485-9.

56. Ramirez OM, Heller L. The anchor tragal flap: a method of preserving the natural pretragal depression during rhytidectomy. Plast Reconstr Surg 2005;116:1115-21. 